\title{
Y AL PRINCIPIO... NO FUE EL VERBO (ESTRATEGIAS PRAGMÁTICAS RELACIONADAS CON LA POSICIÓN DEL SUJETO EN LA CONVERSACIÓN COLOQUIAL)
}

\author{
Xose A. Padilla Garcia \\ Universitat d'Alacant \\ Xose.Padilla@ua.es
}

\begin{abstract}
Resumen
The aim of this paper is to explain what are the implications of the appearance of the subject in Colloquial Spanish. We will emphasize the pragmatic conditionings that account for the use of different constructions. The presence of the subject of the sentence in the Spanish SVO scheme and its position in relation to the verb involve specific pragmatic meanings, which have to do with three main determinining factors: (a) type of verb (accusative or inaccusative), (b) informative characterization of the subject (theme/rheme and topic/comment structure) and (c) context of use. Additionally, all different meanings are logically related to the two conversational roles: speaker and listener.
\end{abstract}

\section{TNTRODUCCIÓN}

El título de este artículo es sólo una anécdota que nos permite recordar una polémica que afecta al orden de palabras en español: ¿debemos tener en cuenta para establecer el orden básico las desinencias verbales? En nuestra opinión, la mejor respuesta es no. Y no parece oportuno utilizar estas desinencias principalmente por dos razones: (a) las desinencias verbales no tienen independencia ni movilidad y (b) los morfemas verbales tienen una categorfa muy distinta de la que tienen los constituyentes oracionales (es decir, el ámbito de las desinencias es la palabra, y el ámbito de los constituyentes, la oración).

En función de esta decisión, proponemos que el orden básico del español no es VSO sino SVO, y proponemos, además, que el orden básico no coincide con el orden más frecuente que, según los datos obtenidos de las conversaciones coloquiales ${ }^{2}$, es (S) $\mathrm{VO}^{3}$.

No utilizar las desinencias verbales para establecer el patrón básico no significa quitarles importancia (las desinencias marcan las concordancias), pero esta cecisión nos permite

\footnotetext{
1 El orden básico del español es SVO, y esto puede justificarse con argumentos diversos: (a) es el orden al que recurrimos cuando nos piden una oración al azar; (b) es el orden al que tienden la mayor parte de las lenguas del mundo; (c) es el orden que mejor refieja la división entre agentes y acciones; etc.

2 Véase Padilla (2001) y (2004).

3 Fl escenario más frecuente cn español coloquial es el sujeto omitido, es decir, que, si la situación lo permite, el hablante suprime el sujeto y deja que el oyente lo recupere del contexto. Entendemos coniexto como contexio verbal y como situación de habla.
} 
considerar que la aparición o no de un sujeto(-constituyente) tiene un valor pragmático determinado, y, lógicamente, este valor pragmático será utilizado por los hablantes.

En los párrafos que sigucn vamos a analizar todos los sujetos que aparecen en las conversaciones coloquiales, deteniéndonos especialmente en el valor pragmático de las difcrentes opciones.

\section{TRFS FSCENARIOS POSIBLES}

Si analizamos los sujetos de una conversación coloquial, nos daremos cuenta de que tres escenarios (o esquemas sintácticos) son posibles: (a) que el sujeto no aparezca:

(1)

A: soy- soy ${ }^{4}$ BLAANCA COMO LA NIEVE

$[X P .84, A .1]: 7$

(b) quc cl sujeto preceda al verbo:

(2)

A: pero es que/ ELLA NO TIENE LA CULPA

[ML.84.A.1]:21

y (c) que el verbo preceda al sujeto:

(3)

A: es que $\mathrm{NO} /$ es/ soy YO y- y- y/ soy YO y- y/ no quiero meterte

[ML.84.A.1]:77

Todas estas construcciones, que proceden de los tres esquemas del sujeto, son gramaticalmente posibles y normativamente aceptables, pero, desde un punto de vista pragmático, el uso de cada una de cllas tiene, como veremos más tarde, una explicación diferente.

Según vimos en el apartado introductorio, el escenario (a) es el escenario más frecuente, $\mathrm{y}$, consecuentemente, el escenario no marcado. Los escenarios (b) y (c), por el contrario, son menos frecuentes que el escenario (a), pero, a diferencia de éste, cada vez que el oyente se encuentre con un sujeto explícito recibirá información pragmática adicional.

Los sujetos explícitos pueden ser de dos tipos: (a) sujetos pronominales y (b) sujetos no pronominales. Los sujetos pronominales señalan normalmente a los participantes, $y$, como veremos, su uso resulta de molivaciones psicológicas o sociales. Los sujetos no pronominales se explican por razones diversas, pero, a diferencia de los anteriores, para explicar su aparición no es preciso hablar directamente de un componente psico-social.

Si, además de lo anterior, tenemos en cuenta la relación del sujeto con el tipo de verbo, podemos volver a definir dos situaciones posibles: (a) que el verbo exija una sola valencia (ir, andar, llegar, etc.) y (b) que el verbo exija dos valencias o más (ver, hacer, cantar, etc.). Los verbos que aparccen en el primer caso suelen llamarse intransitivos o inacusativos ${ }^{6}, y$, como veremos más adelante, se caracterizan porque, en una situación no marcada, el verbo

4 Utilizamos la negrita para marcar los diferentes fenómenos.

5 Todos los ejemplos siguen el sistema de transcripción dẹl Grupo Val.Es.Co. (véase Briz y Grupo Val.Es.Co., 2003).

6 Usaremos también los términos monovalentes o monoactanciales. 
precede al sujcto. Los verbos que aparecen en el segundo caso suelen llamarse verbos acusativos o transitivos, y se caracterizan porque, en una situación no marcada, el sujeto precede al verbo.

Si miramos hacia atrás en el contexto del discurso, los sujetos pueden ser descritos, además, como viejos o nuevos (estructura tema-rema); y si miramos hacia delante, los sujetos pueden ser descritos como tópicos o no tópicos (estructura tópico-comentario). Como veremos más tarde, la posición del sujeto se explicará, pues, por dos causas: (a) por el tipo del verbo (acusativo o inacusativo) y (b) por la caracterización informativa del sujeto (estructura tema-rema + estructura tópico-comentario).

Si tenemos en cuenta 10 dicho hasta el momento, observaremos que el carácter marcado o no marcado de una situación determinada puede proceder de dos vías diferentes: (a) por la simple aparición del sujeto y (b) por la posición que ocupe el sujeto con respecto al verbo. Ambas vías son herramientas gramaticales(-sintácticas) que permiten poner en marcha estrategias pragmáticas.

Todas las razones mencionadas hasta el momento concurren en la descripción pragmática de los sujetos de las conversiones coloquiales. En los apartados siguientes ejemplificaremos todas estas posibilidades, atendiendo al peso mayor o menor de cada uno de los diversos condicionantes.

\section{EN LA APARICIÓN DE LOS SUJETOS PRONOMINALES ACTÚA UN COMPONENTE PSICO-SOCIAL}

Como hemos dicho, los sujetos implícitos son propios de una situación pragmática no marcada, por lo tanto, podemos afirmar que la información que trasmiten en esos momentos del desarrollo conversacional no es especialmente rclevante.

El diálogo del ejemplo (4) señala el instante en el que un nuevo hablante (D) entra en escena. Como la información más importante con respecto a los personajes es trasmitida por la situación de habla, todos los sujetos del ejemplo (4) son sujetos implícitos:

(4)
D: juy!
A: hola Mercedes $\$$
D: $§$ ise puede?
$\Lambda$ : sí sí/ pasa pasa
D: ¿qué pasa?
A: no/ nada/ charrábamos/y eso
D: ¿me voy o me quedo? ¿qué hago? (RISAS)
A: no/ no te preocupes
C: [bueno ¿qué?]
A: [y eso] no sé $/ / /$ (TOSES)

\section{[ML.84.A.1]:5}

Aunque la información trasmitida por estos sujetos no sea contextualmente importante, los sujetos, obviamente, siguen estando ahí, y, el oyente procesa su existencia con el resto de la información. Para hacer esto, el oyente, además de la presencia de los participantes en la conversación $(A, C$ y $D)$, posee la información procedente de las desinencias verbales. 
Es decir, detrás de los verbos charrábamos, hago $\mathrm{y}$, preocupes, se esconde un nosotros, un yo, un $t \dot{u}$, que corresponden a los tres participantes ( $\mathrm{A}, \mathrm{C}$ y D).

\subsection{Sujetos pronominales explícitos}

En la convcrsación coloquial se da una situación paradójica que afecta a los pronombres personales: aunque la situación favorezca los sujetos implícitos, los pronombres personales con función de sujeto son muy abundantes.

Los datos obtenidos del corpus del Grupo Val.Es. $\mathrm{Co}^{7}$, nos permiten presentar las siguientes tablas de porcentajes:

Tabla 1

\begin{tabular}{l|l}
$\begin{array}{l}\text { Sujetos explícitos } \\
\text { pronominales }\end{array}$ & $44^{\prime} 53$ \\
\hline $\begin{array}{l}\text { Sujetos explícitos } \\
\text { no pronominales }\end{array}$ & $55^{\prime} 46 \%$
\end{tabular}

Es decir, en las conversaciones analizadas, hay casi tantos sujetos pronominales como no pronominales. La cifra de los sujetos pronominales puede incluso subir de forma desmesurada, si analizamos conversaciones especialmente polémicas, como la [ML.84.A.1]:

Tabla 2

\begin{tabular}{l|l}
$\begin{array}{l}\text { Sujetos explícitos } \\
\text { Pronominales }\end{array}$ & $77^{\prime} 2 \%$ \\
\hline $\begin{array}{l}\text { Sujetos explícitos } \\
\text { no pronominales }\end{array}$ & $22^{\prime} 7 \%$ \\
\end{tabular}

en la que son mayoría los sujetos explícitos pronominales ${ }^{8}$.

Como hemos visto, para explicar los sujetos pronominales implícitos no necesitamos más que la siluación comunicativa (presencia material de los hablantes), sin embargo, para explicar la aparición de los sujetos explícitos pronominales debemos acudir, como veremos a continuación, a una combinación de causas psicológicas y sociales.

Por causas que llamaremos sociales, los participantes dejan huellas verbales constantes en el discurso que sirven para subrayar la presencia de los papeles conversacionales (yo tú):

(5)

A: $\S$ mira $\downarrow$ yo te quicro// y cre- y creo que lo SABES/// pero NO/ no puedo DEMOSTRÁRTELO $\downarrow$ o sea no- no puedo dedicarte todo lo que tú necesitas

B: pero si yo no te pido que me lo demuestres

ML84:124

7 Un estudio de tipo estadístico aparece en Padilla (2001 y 2004).

8 La conversación [ML.84.A.1] es una riña entre novios. 
Estas huellas reflejan la posesión o no del turno de habla, y, desde el punto de vista de la estructura conversacional, suelen aparecer en LTPs (lugares de transición pertinentes), es decir, en aquellos lugares en los que la situación conversacional propicia la alternancia de turnos:

(6)

E: no $\downarrow$ la cuestión es que yo no soy beata/ la cuestión es que cn mi casa tengo una tía monja y está ahí $\uparrow$ / (enton)ces yo paso totalmente de las monjas- de las monjas y digo más tacos que ;bueno!/ que seguramente cual[quier otro que no $\rightarrow]^{9}$

G: [no/ yo- yo también conozco] mucha gente que ha idoo [L.15.A.1.]:383

Por lo tanto, una de las razoncs para justificar la aparición de los pronombres personales sujeto es hablar de su papel como refuerzo de la condición social de hablantc.

Por causas que llamaremos psicológicas, el hablante necesita acentuar que es él el origen de las diferentes opiniones que se intercambian entre los participantes. Esta necesidad también propicia la aparición de nuevas huellas pronominales.

Fstas huellas pronominales pueden ser de dos tipos: (a) simples señales que indican la fuente de emisión, como en el ejemplo (7)

(7)

A: ¿qué ha- qu'hah hecho pa(ra) cenar?§

C: $\S$ yo no he hecho nada

[RV.114.A.1.]:260

y (b) focos contrastivos ${ }^{10}$, como en el ejemplo (8):

(8)

B: DÍMELO/ NO $\downarrow$ DÍMELO/ ¿TÚ QUIERES QUE ESTÉ YO AQUÍ AGUANTANDO QUE TÚ ESTÉS MAL? ${ }^{11}$

[ML.84.A1.]:223

La diferencia entre los dos tipos de huella verbal deriva de la existencia o no de una estrategia pragmática, cs decir, de la mayor o menor implicación del hablante en los contenidos de su intervención.

Cuando los pronombres son simples huellas de emisión, estas huellas pueden ser eliminadas, y el contenido del enunciado a penas sufre variaciones; cuando los pronombres son contrastivos, es decir, cuando existe una estrategia pragmática detrás de su uso (oposición entre dos elementos ${ }^{12}$ ), nunca pueden ser eliminados sin que se pierda información pragmática.

9 Estos LTPs suelen dar lugar a solapamientos entre los participantes, señalados por convención con dos corchetes.

10 De hecho, la mayor parte de los gramáticos consideran que ésta es la razón principal para explicar la presencia explícita de los sujetos pronominales (véase Alarcos, 1994).

11 Como se trata de la riña entre novios la presencia manifiesta cs yo tí.

12 Ia oposición puede ser in praesentia o in absentia. 
Si comparamos los ejemplos (9) y (10), comprobaremos que mientras en el primer caso el pronombre yo es prescindible, en el segundo caso es imposible suprimirlo sin provocar pérdidas de información nccesarias para comprender el enunciado:

(9)

E: yo mi hi(ja) ee es que no sé [M $\Lambda .341 . A .1.]: 34$

(10)

B: tío// no te quiero agobiar peroo/me gustaría que me dijeras lo que te pasa

A: es que NO/ es/ soy YO $\mathrm{y}-\mathrm{y}-\mathrm{y} /$ soy $\mathbf{Y O} \mathrm{y}-\mathrm{y} /$ no quiero meterte

B: pero quiero que me metas (3»)

$$
\text { [ML.84.A.1]:77 }
$$

Los pronombres contrastivos tienen, además, marcas prosódicas especiales. Es decir, siempre que encontremos uno de estos pronombres hallaremos marcas que indiquen una prominencia prosódica especifica (por convención, la señalamos con las mayúsculas).

Esta promincncia prosódica puede afectar a diversos tipos de elementos: a una sola palabra ${ }^{13}$, como en el ejemplo (11):

(11)

E: vamos a ver/ ser liberal ¿por qué $\uparrow$ YO- yo me rijo por unas normas $\bar{\uparrow}$ y yo conservog̃ unn- yo qué sé

G: $§$ pues ya está

[L.15.A.1]:357

a una oración, como en el ejemplo (12):

(12)

C: pues tio $\downarrow$ cuanto antes/ no vas a estar todo el día esperando

A: pero es que/ ELLA NO TIENE LA CULPA

[ML.84.A.1]:21

o a una intervención completa, como en el ejemplo (13):

(13)

A: ES- ES QUE SON PROBLEMAS MÍOS $\downarrow$ SIMPLEMENTE TENGO OUE ARREGLARME YO/ Y - UNA VEZ QUE ESTÉ ARREGLADO/ SÉ QUE PODRÉ ESTAR BIEN CONTIGO

[ML.84.A1.]:153

Aunque la aparición de estos focos acentuales o entonativos esté menos regularizada que otros fenómenos informativos ${ }^{14}$, su presencia permite realzar ostensiblemente los sujetos, o cualquier otro segmento del discurso, independientemente de la posición que ocupen en el enunciado ${ }^{15}$.

13 Incluso puede afectar a un solo sonido o a una sílaba.

14 Tienen un valor demarcativo menor, es decir, und capacidad menor para segmentar elementos.

15 Véase Hidalgo y Padilla (en prensa). 
La paradoja que anunciábamos al principio se resuelve, pues, de la siguiente manera: aunque la situación favorezca los sujetos implícitos [+participantes], existe una conexión emocional entre el hablante y los contenidos de la conversación. Esta conexión emocional del hablante con lo que dice justifica que los pronombres personales de primera y segunda persona salpiquen las conversaciones coloquiales, pues la relación del hablante con los contenidos que se exponen o intercambian le obliga a manifestarse como tal y a luchar por conservar su papel social. Todo esto explica que, en conversaciones especialmente polémicas, como la [ML.84.A.1], una riña entre novios, los participantes aparezcan de forma explícita en casi todas las intervenciones (véase tabla 2).

\section{EL ORDEN SV/VS DE IOS SUJETOS PRONOMINALES Y NO PRONOMINALES}

Como afirmamos en la introducción, el orden de los sujetos explícitos se explica de dos maneras diferentes: (a) por la caracterización actancial del verbo y (b) por la caracterización informativa del sujeto.

En una situación no marcada, los verbos monoactanciales exigen el sujeto pospuesto:

A: falta un poquillo más de sombra pero vamos $\downarrow$ tampocoo

[H.38.A.1] :12

y los verbos no monoactanciales exigen el sujeto antepuesto ${ }^{16}$ :

B: yo quería un par (( )) de cada/ mujer ieh?

$$
\text { [1H.340 A.1]:165 }
$$

Desde un punto de vista estadístico, los sujetos monoactanciales o inacusativos son minoría. Por lo tanto, es normal que, en el caso de que el sujeto sea explícito, y no atendamos a la valencia del verbo, el orden más frecuente sea SV. Este orden coincide, como vimos en el apartado introductorio, con el orden del patrón básico (SVO).

Si la situación no marcada es VS con verbo monoactancial y SV con verbo no monoactancial, todo tipo de cambio de este orden (o esquema) será producto de una situación marcada, y, por lo tanto, de una estrategia pragmática.

Si partimos de la estructura tema-rema, los sujetos pronominales son siempre [-nuevos], ya que, como hemos visto, cl hablante está presente en la situación y, complementariamente, en las desinencias verbales.

(16)

B: pues entonces me estás dando la razón $\downarrow$ hoy ha llegado el dia en que yo ya- yo ya nono puedo aguantar más la situacióni o sea que tú mismo/ me estás dando la razón/t y tú no podrás aguantar tus motivos/ pero como no me dices los motivos// pues yo estoy hasta el culo y yo ya no sé qué decirte ni qué decirte para que me digas el qué coño te pasa $\downarrow$ si yo creo que ni tú mismo sabes lo que- qué cojones te pasa

[ML.84.A1.]:273

16 Véase Delbecque (1991). 
Los sujetos no pronominales, por el contrario, pueden ser [+nucvos] o [-nuevos], pero serán normalmente [-nuevos] si el hablante desea que el oyente procese la información correctamente.

Cuando se presenta un caso de confusión, como en el ejemplo (17), y el hablante presupone erróneamente que la información es conocida, el oyente resuelve la situación pidiendo información suplementaria.

A: (...) probablemente esto sea muy optimista / / es decir que dé demasiada carga al Cics/ yo creo que el Cics ticne menos carga en el sistema hoy en dia

B: ¿qué es Cies?

A: Cics es el monitor de transacciones dee- de Ibeeme// es un monitor de transacciones

B: ¿qué función hace? (( ))

A: lo de cualquier monitor de transacciones

B: ¡ah! vale

[XP48.A.1]:300

Si partimos de la estructura tópico-comentario, los sujetos pueden caracterizarse indistintamente de cualquiera de las dos formas, es decir, como [+tópicos] o como [-tópicos]. Como vcremos a continuación, esta caracterización informativa de los sujetos está directamente relacionada con la distinción entre verbos monoactanciales (ir, venir; llegar, etc.) y verbos no monoactanciales (tener, comer, comprar, hacer, etc.).

Los verbos monoactanciales, que tienen como no marcado el orden VS, pueden colocar el sujeto cn la posición de tópico trasformando una situación no marcada en una situación marcada (orden SV). En estos casos, diremos que los sujetos se topicalizan a la izquierda, se colocan, como veremos a continuación, en la posición a:

(18)

A: ese era un cerdo

D: [(RISAS)]

B: [(RISAS)]

C: [(RISAS)] escupir y eructar $\uparrow$ era algo- era algo imnato en él

D: $[$ y y $\mathrm{y}=]$

B: [caballeros así ya no salen]

[H.38.A.1.]:496

(19)

L: ¿QUÉ se llama Antonio Juan?

F: no/ Juan Antonio- Antonio Juan

L: ¿cómoo?

E: Antonio Juan/ no ha llegao to(d)avia a SUS aposentos [L.15.A.1.]:51

Los verbos no monocactanciales tienen el orden SV como forma no marcada, y su conversión en tópico se señala, como indican los ejemplos, de dos formas diferentes: (a) por la presencia de un tonema (normalmente ascendente $\uparrow$ ): 
(20)

E (...) es que yo $\uparrow$ respeto mucho lo que dice la gente [L.15.A.1.]: 346

y (b) por la presencia de un segmento de peso ${ }^{17}$ que separe sujeto y verbo.

(21)

E: yo sí/ liberaal- soy conservadora enn-/ pues en lo que interesa como to'l mundo/t pero vamos no soy nada liberal $\uparrow$ lo contrario/// lo que pasa $\uparrow$ es que yo respeto mucho lo que dice la gente/ a mi- cada uno que haga lo que quiera yy§

L: $\quad \S$ yo por ejemplo no lo haría [L.15.A.1]:347

Ambas formas de marcaje pucden actuar de manera simultánea, como ocurre en el ejemplo (22):

(22)

E: Juan

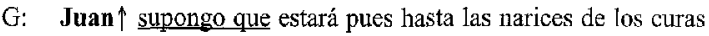
[L.15.A.1.]: 402

Desde un punto de vista predicativo, el verbo suele ser un comentario del sujeto, de ahí que, en la gramática tradicional, se hable de sujeto y predicado. Esto ha llevado a autores como Givón (1979) a proponer que en realidad los sujetos derivan de una gramaticalización del tópico. Habría pruebas de la relación tópico sujeto en ejemplos como el (23) en donde el conjunto yo para mí $\uparrow$ parece antes un tópico que un sujeto ${ }^{18}$ :

(23)

E: es que/ es que ee yo para mil el hecho de ser conservadores y talal precisamente radica en sus principios/ y para mi hay unas- unos valores// muy fundamentales que a lo mejor para otra persona no lo son ¿no?/// (3") no sé

$$
\text { [L.15.A.1.]:377 }
$$

En nuestra opinión, el sujeto podría considerarse una gramaticalización del tópico porque ocupa normalmente una posición relevante (posición a), y esto es independiente de la caracterización actancial del verbo. Esta hipótesis se apoya en el comportamiento de los ejemplos del corpus, pues los sujetos antepuestos, como se observa en la tabla $3^{19}$ :

Tabla 3

\begin{tabular}{l|l} 
Orden SV & $82 \% 19 \%$ \\
\hline Orden VS & $17 \% 80 \%$
\end{tabular}

17 Con elemento de peso nos referimos a aquellos que tengan suficiente sustancia fónica (número de sílabas) como para separar el sujeto. Por ejemplo, hay adverbios con muy poco peso fónico que no consiguen romper el contomo melódico, y, por lo tanto, no topicalizan el sujeto: Yo también bailó tangos.

18 Ésta suele ser la norma en lenguas como el chino (véase Padilla, 2001).

19 Los datos no hacen difcrencias entre sujetos pronominales y no pronominales (véase Padilla, 2001, 2004). 
son mayoría, y, por lo tanto, aparecen de forma habitual en la primera posición preferente (posición a).

Si tenemos en cuenta condicionamicntos pragmático-perceptivos ${ }^{20}$, podemos proponer la existencia de dos posiciones pragmáticamente relevantes: la posición a y la posición $\mathbf{b}$. Estas posiciones permiten que hablemos de topicalizaciones a la izquierda y topicalizaciones a la derecha.

Figura (1)

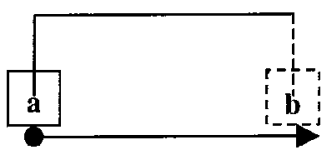

Siendo a la primera posición; b, la última; y la flecha, la dirección del flujo de información.

Los verbos, monoactanciales y no monoactanciales, pucden colocarse en cualquiera de cstas posiciones y destacarse, utilizando diversos mecanismos según sea su sistema de orden neutro (SV o VS).

En el caso de los verbos monoactanciales, como hemos visto, tendremos topicalizaciones cuando se cambie el orden del sujeto (ejemplos 18 y 19); y en el caso de los verbos no monoactanciales, tendremos topicalizaciones cuando el sujeto se sitúe en cualquiera de las dos posiciones relevantes de la figura 1 (a y $\mathbf{b}$ ).

Si el sujeto de un verbo no monoactancial se sitúa en la posición $\mathbf{b}$, como en el ejemplo (24), se topicaliza por posición:

A: no/ lo que pasa es que a ver si la suerte la he tenido yo

[M.T.97.A.1.]: 34

si el sujeto se sitúa en la posición a, necesita, sin embargo, un medio de topicalización suplementario: un tonema o un segmento interpuesto, como sucedia en los ejemplos (20), (21) y (22).

\section{El ENTORNO PRESENIATIVO}

Para todos aquellos casos en los que los sujetos aparecen en posición posverbal, algunos autores ${ }^{21}$ proponer utilizar el término entorno presentativo.

En realidad, el entorno presentativo es un entorno en el que el sujeto pasa a segundo plano, por lo tanto, se coloca en posición posverbal. Los verbos monoactanciales se acomodan mejor a este entorno porque su forma no marcada es VS, como en los ejemplos (25) y (26):

20 Véase Padilla (2004).

21 Véase Hatcher (1956) o Suñer (1982). 
(25)

V:no-nocs que ahí salen horribles/ todos ${ }^{22}$

[IH.340.A.]: 86

(26)

A: y ahí van dos huevos con el agujero aquí abajo ${ }^{23}$

[IH.340.A]:89

pero los verbos no monoactanciales pueden igualmente acoplarse a cl, cambiando su orden habitual SV por el orden VS:

B: luego con gusto pagaría yo un cubata/ sii te la follas

[H.38.A.1]: 111

Como los sujetos que se adaptan a este entorno están en la posición $\mathbf{b}$, son, desde un punto de vista informativo, información adicional que sirve para matizar o completar la información anterior:

A: mira esto que me ha regalado Toni/ para reyes ${ }^{24} \S$

[HI.340.A.1.]:58

B: si es que son así los hombres

[EL.116.A.1.]: 6

La presión del entorno presentativo explica que algunos verbos impersonales hayan cambiado su estructura sintáctica habitual, y pasen del esquema impersonal al esquema presentativo. Esto aclara vulgarismos como:

(30)

A: pues en mi casa habían a lo mejor seis o siete discos de Bruno Lomas

[XP.84.A.1]:90

pues el hablante siente que el objeto directo (seis o siete discos de Bruno Lomas) es en realidad un sujeto, y esto le conduce a conjugar el verbo como si se tratara de un verbo personal (*habian coches, *hubieron doscientas personas, etc.).

Independientemente del tipo de verbo, los sujetos pospuestos, a no ser que sean contrastivos (véase ejemplo 10), son información complementaria, en el sentido de que suman información ${ }^{25}$, y de ahí que el sujcto aparezca pospuesto (posición b).

Pero cuando encontramos un sujeto pospuesto no sólo debemos entender que cl sujeto se desdibuja, sino tambićn que su relación con el verbo se entiende como un bloque de acción más compacto. Fs lo que sucede en los ejemplos (31) y (32):

22 Está hablando de unas fotos.

23 Se refiere a un utensilio para colocar huevos.

24 Se refiere a un anillo, regalo de Navidad.

25 En inglés se utiliza el término afierthought y en italiano ripensamenti, que tienen también un sentido de complementariedad. 
(31)

B: ¡CLARO!/ es que

$\Lambda$ : \$ y empieza el tío /me cago en Diós' me cago en Dios!

B: , , eh que/ tú te lo imaginaṣ que le tengas que dạ̃r unos calzoncilloṣ ¡me cachis la mar!/ eh que no lo entiendo (( ))

[EL.116]: 9

(32)

$\mathrm{V}$ : no-noes que ahí salen horribles/ todos ${ }^{26}$

[IH.340.A.1]: 86

Con el orden SV ocurre todo lo contrario, el sujeto mantiene su independencia, y el hablante abre nuevas líneas de desarrollo o argumentación en el diálogo (posición a):

(33)

G: igual [que Juan ${ }^{27}$ ¿no? $=$ ]

E: $\quad$ [у y y]

$\mathrm{G}: \quad=$ lo llamas Juan ¿no?

E: Juan

G: Juan supongo que estará pues hasta las narices de los curas $\S$

E: $\S$ no/ Juan no/ Juan es un ((beato))

(RISAS)

[L.15.A.1.]:398

La mayor parte de los sujetos (sean o no pronominalcs) que sc colocan cn posición preverbal son sujetos personales. Por lo tanto, nuestros ejemplos parecen cumplir lo que Kuno (1967) llamó principio de empatía del hablante, según el cual, si tenemos que decidir entre personas o cosas, colocamos los elementos referidos a personas, delante. Es lógico que esta norma funcione en un corpus de conversaciones coloquiales, pues, como hemos visto, una parte muy importante de los sujelos que encontramos corresponden a los participantes ${ }^{28}$.

\section{FóRMULAS FIJAS CON SUIETUS PRONOMINALES}

Si analizamos cicrtas combinaciones de sujeto y verbo que están formadas por dos únicos elementos, siendo uno de ellos un pronombre, podemos proponer la existencia de una scric de construcciones especiales o fórmulas fijas que poseen un matiz modalizador.

Estas fórmulas fijas, que califican globalmente la totalidad del contenido del enunciado, presentan, además, un proceso incipiente de gramaticalización. Si seguimos las tcorias expuestas anteriormente, la explicación de este proceso de gramaticalización habría que buscarla en la posición posverbal del sujeto, que indica, como hemos visto, un cierto grado de fusión del sujeto con la acción. Desde una perspectiva gestáltica, podría decirse que, en todos los casos de sujeto antepuesto (yo pongo), el verbo es cl fondo y cl sujcto la figura; y que, cuando el sujeto está pospuesto (pongo yo), ocurre lo contrario. Como consecuencia

26 Está hablando de unas fotos.

27 Se trata de Antonio Juan, novio de L, personaje al que ya se ha aludido con anterioridad.

28 Véanse tablas 1 y 2. 
de esta fusión, cl sujcto de la fómula discursiva queda desdibujado, se funde con el fondo dando lugar a una sola unidad (pienso yo, digo yo, creo yo, etc.).

Figura 2

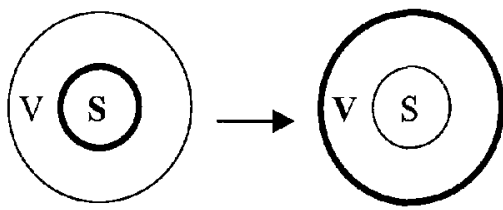

Sicndo V (verbo) y S (sujeto).

De ser cierto todo lo antcrior, podría argumentarse que combinaciones como pienso yo, creo yo, etc. funcionan, pues, como una especie de marcadores discursivos con matiz moralizador similar a no sé, o a adverbios como seguramente, simplemente, etc.:

(34)

$\mathrm{B}: \quad$ = que cuando era pequeña $\uparrow$ a una chacha que había en mi casa le escribieron unas cartas de aquellas/ y aquella me hacía cscribirlc porque no sabía ni escribir/ pero que ahora por internet [((se puede escribir $))=]$

A: [jchica! no sabía yo]

C: [yo en la vida/ EN LA VIDA $\downarrow$ en la vida]

[MT.97.A.1]:291

A: y que la mayoría pues funcionan $\uparrow /$ pues mira/como videncia $\uparrow /$ no sé cómo decirte/ no hay que cstudiar nada $\uparrow$ y se lo nota $\uparrow$ uno/ hay muchos que dicen que se lo notan/ y a lo mejor pues lo que pienso yo que no lo son sino que más bien son sicólogos§

C: $\$$ son buenos psicólogos/ buenos $\$$

[MT.97.A.1]:84

(36)

$\mathrm{A}: \quad=$ ver estos recipientes que yo pongo aquí de manera totalmente subjetiva// cuál es la- porque claro hay quien para- pienso yo que para modelizar la carga habrá que saber/ cuál es la carga

B: $\quad$ exacto $§$

[XP.48.Al]:325

\section{CONCLUSIONES}

Como hemos podido comprobar en los apartados anteriores, la aparición de un sujeto y su posición con respecto al verbo se explican por una conjunción de causas sintácticas y pragmáticas.

La aparición del sujeto está condicionada siempre por la situación, y esto afecta sobre todo a los sujetos pronominales. Hemos hablado, además, de la importancia en estos casos de motivaciones psico-sociales. 
La posición del sujeto depende de dos tipos de causas: (a) del tipo de verbo y (b) de la caracterización informativa del sujeto.

E1 tipo de verbo nos proporciona información sobre cuál es su orden no marcado. En el caso de los verbos monoactanciales, este orden es VS, y, en el caso de los verbos no monoactanciales, este orden es SV. La caracterización informativa del sujeto, que depende en realidad de la caracterización sintáctica anterior (+-monoactancial), nos indicará si el orden del sujeto responde a motivaciones pragmáticas, es decir, si está o no topicalizado.

Como la mayor parte de los sujetos de una conversación coloquial son sujetos personales, los ejemplos cumplen, como hemos visto, la regla de Kuno (1976) del principio de empatia del hablante, es decir, que los elementos que tienen que ver con personas van siempre delante.

Cuando los sujetos no están en primera posición (sean o no personales) se desdibujan, se funden con la acción, y desde un punto de vista gestáltico, pasan de ser figura a ser fondo perceptivo. Esto permite proponer un proceso de gramaticalización incipiente en ciertas construccioncs con sujeto pospuesto como pienso yo, digo yo, etc.

\section{REFERENCIAS BIBLIOGRÁFICAS}

Alarcos, E. (1994): Gramática de la lengua española. Madrid, Espasa-Calpe.

Bello, A. (1847): Gramática de la lengua castellana destinada al uso de los americanos. París, A. Roger y F. Chervoviz Editores, (1905).

Bentivoglio, P. (1992) «La estructura argumental preferida del español modemo», en: Vaquero, Maria/Morales, Amparo, (eds.) Homenaje a Humberto López Morales; Madrid: Arco Libros. pp. 107-120.

Bentivoglio, P. y D'Introno, F. (1978), «Análisis sociolingüístico del español de Caracas: el orden de las palabras y la posición del sujeto», Universidad de Puerto Rico.

Bosque, I. y Demonte, V. (1999) (coor.): Gramática Descriptiva de la Lengua Española, Madrid: Espasa-Calpc.

Bravo, D., «Hacia una semiótica de la identidad social: gestos en la manifestación de ideales de la personalidad socio-cultural en discursos académicos», Oralia, 3, págs. 21-51, 2000.

Bravo, D), La atemuación de las divergencias mediante la risa en negociaciones españolas y suecas, Estocolmo, Universidad de Estocolmo, 1993.

Bravo, D., La risa en el regateo: Estudio sobre el estilo comunicativo de negociadores españoles y suecos, Estocolmo, Universidad de Estocolmo, 1996.

Briz, A. (1993a): «Los conectores pragmáticos en español coloquial (I): su papel argumentativo», Contextos, XI, 21/22, págs. 145-188; ampliado en Briz (1998: cap. 7).

Briz, A. (1993b): «Los conectores pragmáticos en español coloquial (II): su papel metadiscursivo», Español Actual, 59, págs. 39-56; ampliado en Briz (1998: cap. 8).

Briz, A. (1994): «Hacia un análisis argumentativo de un texto coloquial. La incidencia de los conectores pragmáticos, Verba, 21, págs. 369-395.

Briz, A. (1995): La atenuación en la conversación coloquial. Una categoría pragmática», en Cortés, L. (ed.), El español coloquial (Actas del I Simposio sobrc análisis del discurso oral). Almería, 23-25 de noviembrc de 1994). Almería, Servicio de Publicaciones, págs. 103-122; ampliado en Briz (1998: cap. 4 y 6 ).

Briz, A. (1996a): El español coloquial: Situación y uso. Madrid, Arco-Libros.

Briz, A. (1997): “Los intensificadores en la conversación coloquial», en Briz, A., Gómez Molina, J.R., Martínez Alcalde, M.J. y grupo Val.Es.Co. (eds.), págs. 13-36, ampliado en Briz (1998: cap. 4 y 5 ). 
Briz, A. (1998): El español coloquial en la conversación. Esbozo de pragmagramática. Barcelona, Ariel.

Briz, A. (2000a): «El análisis de un texto oral coloquial», en A. Briz y Grupo Val.Es.Co. (2000), págs. 29-48.

Briz, A. (2000b): «La variedad coloquial en el aula de lengua extranjera. Pautas para el análisis léxicos, Revista Carabela, 47, págs. 37-51.

Briz, A. (2000c): «El español coloquial en los textos», en J. A. Moya (ed.):, Adquisición y enseñanza de la lengua española. Granada, págs. 13-37.

Briz, A. (2001): «El uso de o sea en la conversación», en J. de Kock (ed.):, Gramática española, enseñanza e investigación: Lingüística con corpus. Catorce aplicaciones sobre el español. Salamanca. Ediciones Universidad, págs. 287-318.

Briz, A. (coord.): (1995): La conversación coloquial (Materiales para su estudio). Anejo XVI de la Revista Cuadernos de Filologia. València, Universitat de València.

Briz, A. (en prensa):, El español coloquial a trovés de los textos. Guía didáctica para la clase de Español como Lengua extranjera. Madrid, SGEL

Briz, A. y Hidalgo, A. (1998): «Conectores y estructura de la conversación ${ }^{2}$, en $\mathrm{M}^{\mathrm{a}} \mathrm{A}$. Martín Zorraquino y E. Montolío (eds.): Marcadores del discurso. Teoría y Análisis. Madrid, Arco-Libros, págs. 122-142.

Briz, A., Gómez Molina, J.R., Martínez Alcalde, M.J. y grupo Val.Es.Co. (eds.): (1997): Pragmática y gramática del español hablado. El español coloquial. Zaragoza, Pórtico.

Briz, A. y grupo Val.Es.Co. (2000): ¿Cómo se comenta un texto coloquial. Barcelona, Ariel-Practicum.

Briz, A. y grupo Val.Es.Co. (2003): Corpus de conversaciones coloquiales, Madrid, Arco-Libros (anejo a la revista Oralia).

Delbecque, N. (1991): El orden de los sintagmas (la posición del regente). Salamanca, Universidad de Salamanca.

Gallardo, B. «La transición entre turnos conversacionales: silencios, solapamientos e interrupciones, Contextos $X I$, núm. 21-22, págs 189-220,1993.

Gallardo, B., Análisis conversacional y pragmática del receptor, Valencia, Epistcme, 1996.

Gallardo, B., Comentario de textos conversacionales II. Los textos, Madrid, Arco-Libros, 1998.

Gili Gaya, S. (1961): Curso superior de sintaxis española. Barcelona, Vox (1976).

Givón, T. (1979): «From discourse to Syntax: grammar as a procesing strategy», Syntax and Semantics: Discourse and Syntax, Vol. XII. Nueva York, Academy Press.

Givón, T. (1983) (ed.): Topic Continuity in Discourse: Quantitative Cross-Language Studies, Amsterdam, Benjamins.

Givón, T. (1984): Syntax: A Functional-Typological Introduction, Amsterdam, Benjamins.

Givón, T. (1992): «On interpreting text-distributional correlations: some methodological issucs», Payne, D. L., (1992): Pragmatics of Word Order Flexibility. Amsterdam, J. Benjamins Publishing Co.

Hatcher, A. (1956): «Theme and underlying Question. Two studies of Spanish Word Order», Suplemento de Word, 3, 1956.

Hernanz, Ma L., y Brucart, JM. (1987): La sintaxis, Barcelona, Editorial Crítica, pp. 70-106.

Herrero, G. (1998): «La importancia del concepto enunciado en la investigación del español coloquial: a propósito de los enunciados suspendidos» Actas del II Simposio de Pragmática y gramática del español hablado. Zaragoza, Pórtico.

Hidalgo, A. (1997a): Entonación coloquial. Función Demarcativa y Unidades de Habla. Valencia. Universitat de València, Anejo XXI de Cuadernos de Filologia.

Hidalgo, A. (1997b) «Notas para cl estudio de la entonación como factor integrador y delimitador de enunciados en el habla espontánea», Actas del I Congreso de Lingüisitica Gerieral (Panorama de la investigación ingüistica en el Estado Español), págs. 14-27. 
Hidalgo, A. (1997c): «La estructura del discurso oral, en torno a las funciones lingüísticas de los suprasegmentos en la conversación coloquials, Quaderns de Filologia. Estudis Lingüistics II. Valencia, Universitat de València, págs. 147-165

Hidalgo, A. (1998a): «Alternancia de turnos y conversación. Sobre el papcl regulador de los suprasegmentos en el habla simultánea», Lingüística Española Actual, 20/2, págs. 217-238.

Hidalgo, A. (1998c): «Expresividad y función pragmática de la entonación en la conversación coloquial, Algunos usos frecuentes», Oralia, 1, págs. 69-92

Hidalgo, A. (2000): «Funciones de la entonación en la conversación coloquial», en Briz y grupo Val. Es.Co., págs. págs. 265-284.

Hidalgo, A. (en prensa a): «Reconocimicnto de unidades en el discurso oral: el Acto y el Subacto como segmentos menores del análisis», Homenaje a Antonio Quilis. UNED.

Hidalgo, A. (en prensa b): «Microestructura discursiva y segmentación informativa en la conversación coloquial», ELUA. Universidad de Alicante.

Hidalgo, A. y Padilla García, X.A. (en prensa): «Topicalización y prosodia».

Kuno, K. (1972), «Functional sentence perspective: A case study from Japanese and Finglish», Linguistic Inquire 3, pp. 269-320, 1972.

Kuno, S. (1976): «Subjcet, theme and the speaker's empthy; a reexamimnation of relativation phenomenas, en Li ed., pp. 627-672.

Kuno, S. y Kaburaki, E. (1977): «Empathy an Syntax», cn LE, 8, pp. 627-72.

Li, C.N. (ed.) (1975): Word Order and Word Order Change, Austin, University Tcxas Press.

Li, C.N. (ed.) (1976): Subject and topic, New York, Academy Press.

López Meirama, B. (1997): La posición del sujeto en la cláusula monoactancial en español, Santiago, Universidade de Santiago de Compostela, 1997.

Martíncz Caro, E. (1998): "Parallel focus in English and Spanish: evidence from conversation», en Hannay y Bolkenstein (cd.), Functional Grammar and Verbal intertion, Amsterdam, Benjamins, pp. 215-242.

Martínez Caro, E. (1999): Gramática del discurso: foco y énfasis en inglés y en español, Barcelona, PPU.

Moreno Cabrera, J.C. (1985): «Típología de la catáfora paratáctica: entre la sintaxis del discurso y la sintaxis de la oración», en ELUA, 3, Págs. 165-192.

Morcno Cabrera, J.C. (1987): Fundamentos de sintaxis general. Madrid, Síntesis.

Narbona, A. (1989): Sintaxis española: nuevos y viejos enfoques. Barcelona, Ariel.

Padilla García, X.A. (1996): «Orden de palabras en español coloquial: Problemas previos a su estudio» en Briz, A., Gómez Molina, J.R., Martinez Alealdc, M.J. y grupo Val.Es.Co. (eds.), Zaragoza: Pórtico, 343-351.

Padilla García, X.A. (2000): «El orden de palabras», en Briz, $\Lambda$. y grupo Val.Es.Co. (ed.), ¿Cómo se comenta un texto coloquial?, Barcelona, Ariel. Págs. 221-242.

Padilla García, X.A. (2001): «Orden de palabras y español coloquial: estrategias sintácticas, semánticas c informativas», en Actas del I Congreso Internacional de Análisis del Discurso, Lengua, Discurso, Texto, Volumen I, Madrid: Visor.

Padilla García, X.A. (2001b): «Análisis pragmático del orden de palabras en enunciados coloquiales», en Cuestiones conceptuales y metodológicas de la lingüistica, $\mathrm{n}^{\circ} 10$ de la colección «Lucus Lingua» (serie anexa a la revista Moenia), Santiago, Universidade de Santiago de Compostela.

Padilla García, X.A. (2001c): El orden de palabrus en el español coloquial (tesis doctoral), Valencia, Universitat de València.

Padilla García, X.A. (2003): «Los papeles comunicativos y las unidades conversacionales», Actas del Congreso Alonso Zamora Vicente (Los clásicos, los contemporáneos), Alicante, Universidad de Alicante.

Padilla García, X.A. (2004): Pragmática del orden de palabras, Alicante, Publicaciones de la Universidad de Alicante. 
Padilla (en prensa a): «Del oyente receptor al oyente combatiente (la función de las unidades conversacionales en la definición de los papeles comunicativos)m.

Padilla (en prensa b): «El problema del patrón básico desde la teoría de prototipos (su aplicación al orden de palabras en español)»\%.

Payne, D.L. (1992): «Nonidentificable information and pragmatic order rules in 'O'odham», Payne, D. L., (1992): Pragmatics of Word Order Flexibility. Amsterdam, J. Benjamins Publishing Co.

Pons, S. (1998): Conexión y conectores. Valencia, Universitat de València, Anejo XXVII de Cuadernos de Filologia.

Prince, E. (1975): «Toward a Taxonomy of Given-New Information», en P. Cole (ed.), Radical Pragmatics, Nueva York, Academic Press.

Prince, E. (1985):» Fancy syntax and shared Knowledege», en Journal of Pragmatics, 9.

Rivero, ML. (1980): «On left-dislocation and topicalization in Spanish», en Linguistic Inquire, 11, págs. 363-393.

Suñer, M. (1982): Syntax and Semantic of Spanish Presentational Sentences Types. Whasington D.C., Georgetown University Press.

Zubizarrcta, M.L. (1998): Prosody, focus, and word-order, Cambridge, MA., MIT Press.

Zubizarreta, M. L. (1999): «Las funciones informativas: tema y foco», en I. Bosque y V. Demonte (coords.): Gramática Descriptiva de la Lengua Española, Madrid: Espasa-Calpe, págs. 4215-4244. 